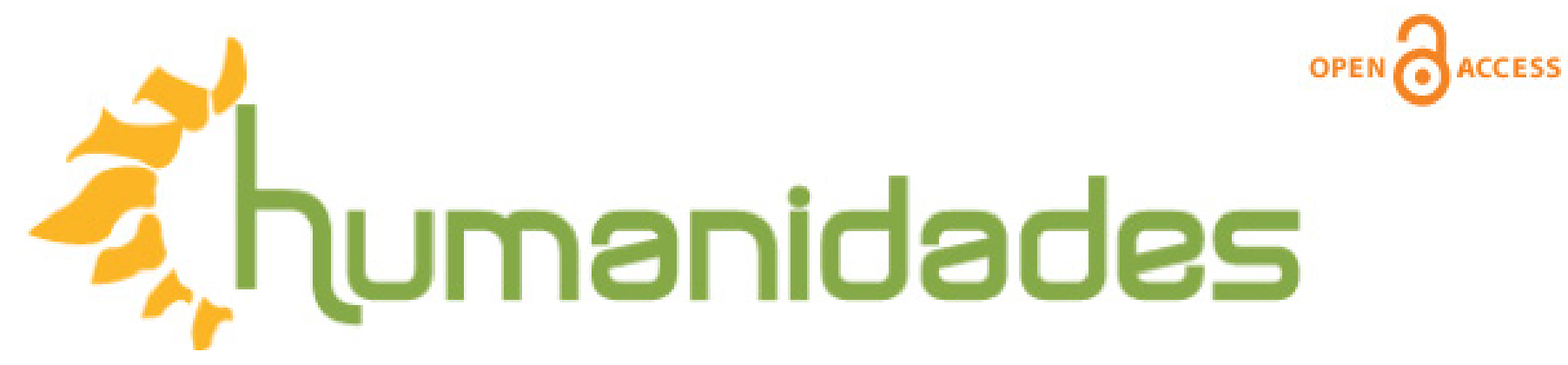

Revista de la Escuela de Estudios Generales, Universidad de Costa Rica

Julio-diciembre, 2018 •Volumen 8, número 2 • EISSN 2215-3934 •pp. 1 - 27

Recibido: 23-Marzo-2018 Aceptado: 18-Abril-2018

\title{
Exposiciones de arte global como idearios de redefinición geopolítica y social a finales del siglo $\mathrm{XX}$
}

DOI: https://doi.org/10.15517/h.v8i2.33672

\section{Renata Ribeiro dos Santos}

Doctora en Historia. Departamento de Historia del Arte, Universidad de Granada, España.

Correo electrónico: renataribeiro@ugr.es

Todos los derechos reservados. Universidad de Costa Rica. Esta revista se encuentra licenciada con Creative Commons. Reconocimiento-NoComercial-SinObraDerivada 3.0 Costa Rica. Correo electrónico: humanidades@ucr.ac.cr/ Sitio web: http: //revistas.ucr.ac.cr/index.php/ humanidades 


\section{Exposiciones de arte global como idearios de redefinición geopolítica y social a finales del siglo XX}

\section{Resumen}

Profundos acontecimientos ocurridos a nivel político, económico y social en las décadas finales del siglo XX modificaron los cimientos de la configuración geopolítica mundial hasta aquel momento erigidos. El sistema de interpretación del arte, reflejo directo de las relaciones de poder establecidas en los demás estamentos, también fue permeado e influido por estos cambios. Los discursos poscoloniales y multiculturales que exigían una representación ecuánime de los distintos espacios y culturas, fueron uno de los móviles de la modificación de los modelos de las muestras de arte, que codiciarían alcanzar las llamadas "exposiciones de arte global".

Este artículo propone una visión panorámica de exposiciones pensadas y realizadas dentro de este característico contexto, que pueden considerarse como precursoras y promotoras de esta tipología interpretativa del arte global. En una selección y descripción de muestras compuesta por Magiciens de la Terre, las primeras ediciones de la Bienal de La Habana, The Decade Show: Frameworks of Identity in the 1980s y en dos ediciones de la documenta, se analizará cómo, desde distintos preceptos teóricos, estos eventos diseñaron y trazaron el campo de representación y representatividad del "otro".

\section{Global art exhibitions as ideals of geopolitical and social redefinition at the end of the 20th century}

Palabras claves: arte contemporáneo, exposición, arte global, geopolítica.

\footnotetext{
Abstract

PProfound political, economic and social developments in the final decades of the 20th century changed the previously established foundations of the global geopolitical configuration. The system of art interpretation, a direct reflection of the power relations established at the other levels, was also permeated and influenced by these changes.
} 
Exposiciones de arte global...

The post-colonial and multicultural discourses that called for a fair representation of the different spaces and cultures were one of the motives for modifying the models of the art exhibitions, that sought to become the so-called "global art exhibitions".

This article offers a panoramic view of exhibitions created and produced within this characteristic context, which can be considered as precursors and promoters of this interpretative typology of global art. In a selection and description of exhibitions composed by Magiciens de la Terre, the first editions of the Havana Biennial, The Decade Show: Frameworks of Identity in the 1980s and in two editions of the documenta, this article will analyse how, from different theoretical precepts, these events designed and traced the field of representation and representativeness of the "other".
Keywords:

contemporary art, exhibitions, global art, geopolitical. 
Las últimas décadas del siglo XX fueron escenario de numerosos acontecimientos de orden social, económico y político que cambiaron profundamente la organización geopolítica mundial. Sucesos como el retorno a regímenes democráticos en países de distintas regiones — como Latinoamérica, España y Portugal—, la caída del muro de Berlín y el derrumbe del modelo socialista de los países del Este en su deriva hacia el capitalismo; fueron muestra de las incisiones que se produjeron y que calaron profundamente en los más distintos ámbitos de la sociedad. Como impulso y derivaciones de estos cambios se sistematizaron una serie de discursos como el Poscolonialismo, el Decolonialismo, la Alteridad y la Multiculturalidadque comenzaron a exigir una representación cultural igualitaria de las regiones periféricas. En este contexto, también irrumpieron discusiones que revisaron cómo las formas de representaciones del "otro" se construían desde el centro hegemónico (léase Estados Unidos y Europa Occidental).

En líneas generales y de manera simplificada, podemos decir que el detonante - al menos el oficialmente (re)conocido - de la irrupción de los discursos de identificación de los márgenes se sitúa en 1978 con la publicación del libro Orientalismo del escritor y académico palestino Edward Said. En este texto, el escritor establece una historia de verdades construidas por Occidente para representar y controlar simbólicamente el Oriente. Said vislumbra que la lógica de pensamiento de Occidente es binaria: construye su identidad basándose en la alteridad. En este sentido, Said escribe en el epílogo de una edición revisada en 1995 y posteriormente publicada en 2004:

la creación de una identidad (ya sea la de Oriente u Occidente, la de Francia o Gran Bretaña, si bien es claramente un depósito de distintas experiencias colectivas, es, en última instancia, una creación), implica establecer antagonistas y "otros" cuya realidad esté siempre sujeta a una interpretación y a una reinterpretación permanentes de sus diferencias con "nosotros". p. 436

La elaboración de estos discursos comienza a gestarse en distintos espacios geográficos que habían sido colonizados (o mantenían su condición colonial). 
En India la teoría poscolonial se construyó — personificada en la tríade Ranijit Guha, Homi K. Babha y Gayatri Spivak — de la experiencia vivida en plena transición del Imperio colonial británico a la independencia. Mientras que la teoría poscolonial latinoamericana, el decolonialismo, surge dentro del propio ambiente poscolonial. El discurso en América Latina, además de nutrirse del pensamiento poscolonial coetáneo, se decanta por elementos propios, como la teología de la liberación de las décadas de 1960 y 1970. Resulta imprescindible entender que hay una diferencia geopolítica y representacional entre las Américas y el Oriente en el terreno poscolonial: mientras Latinoamérica puede considerarse como una extensión occidental, los países de Oriente encarnan la Otredad de Occidente.

En este contexto, pensadores de América Latina desarrollaron una serie de concepciones para entender, consolidar y afirmar su identidad dentro de esta configuración internacional. El sociólogo peruano Aníbal Quijano (1991) plantea la noción de colonialidad del poder, que explica cómo se perpetúan los sistemas de clasificación y aspiración occidentalistas que estructuran al europeo como modelo universal. El argentino Walter Mignolo (2003) propone una opción decolonial que evidencia el continuismo entre lo hispano y lo criollo posterior a las Independencias del siglo XIX, situando las nacientes repúblicas latinoamericanas como parte del proceso del colonialismo.

Si entrada la década de 1980 estos debates estaban en efervescencia en el mundo académico, algo distinto pasaba en las exposiciones de arte que "ajeno a los debates que se estaban produciendo en el contexto poscolonial, parecía todavía aferrado a la idea de proclamar una única y universalmente válida idea de arte" (Guasch, 2016, p. 103). De modo que este fue el momento de una necesaria "reubicación del arte de las culturas colonizadas, el de las minorías emergentes, el de las áreas periféricas [...], reubicación que supuso reconocer, primero, la existencia de ese 'otro' múltiple y, luego, su capacidad transgresora y su alteridad" (Guasch, 2000, p. 557).

Atendiendo a las discusiones teóricas y la urgente demanda de la inclusión del ‘otro' en las muestras de arte contemporáneo, las instituciones europeas junto con los Estados Unidos se lanzaron a finales de la década de 1980 a una copiosa, aunque perezosa, actividad de producción de exposiciones de arte de regiones periféricas. 
Perezosa porque, al menos en estos inicios, planteará un uso distendido de una idea de culturas foráneas y homogeneizadas basadas en aspectos cercanos a lo subalterno, a lo folclórico y a lo primitivo. Según palabras de Pacheco (1999): "En estas muestras se unen de manera perversa la visibilidad que otorga la postmodernidad a los márgenes con la clara persistencia de criterios que aún se refieren a esos márgenes con las mismas imágenes simplificadas de la modernidad” (pp. 131-132).

En este artículo realizaremos una panorámica por algunas de las exposiciones que funcionaron como detonante de este proceso de inclusión del arte periférico en los sistemas centrales del arte o, como se dio a conocer, haremos diversas reflexiones sobre algunas "exposiciones globales de arte". Aunque algunas muestras ya fueron ampliamente debatidas en otros estudios, creemos que se hace necesario volver a estos modelos, estudiarlos como conjunto y proponer un análisis desde distintas ópticas. Comprender estos modelos iniciales nos puede ayudar a entender la complejidad del momento histórico en que ocurrieron y cómo este fue reflejado en las teorías y en los conceptos barajados en las salas de exposición.

\section{1. "Exposiciones de arte global": los modelos iniciales.}

\subsection{La Bienal de La Habana}

En general, vemos que los estudios sobre "exposiciones de arte global" comenzaron con el análisis de Magiciens de la Terre, muestra exhibida en París en 1989. En este texto vamos a subvertir estos códigos y dar a la Bienal de la Habana la posición preferente en esta andadura. Pues, si bien es cierto que en la primera edición de 1984 la cita habanera no incluyó a artistas de todas las latitudes del globo, el deseo de abrir un espacio de representación para el arte periférico y descentrado fue latente desde su concepción, y se concretó posteriormente en el segundo certamen del año 1986.

La Bienal de La Habana es la primera muestra de arte contemporáneo que consigue establecerse fuera del eje Europa/Estados Unidos, que eran quienes elegían hasta entonces qué era lo que se debería de exhibir de manera global. 
Exposiciones de arte global...

Además, huye de modelos de bienales como las de Venecia y São Paulo — las dos grandes citas hasta aquel momento - pues no se centra en los artistas y tendencias establecidos en el espectro hegemónico/occidental buscando alternativas a las representaciones y a los envíos nacionales.

La primera edición de la Bienal en 1984 (figura 1) se centró en artistas de América Latina, aunque su intención global se mostraba presente desde sus inicios. De acuerdo con el documento fundacional del Centro Wifredo Lam —institución responsable del evento- sus atribuciones y funciones eran:

el estudio y promoción de la obra de Lam como expresión universal de arte contemporáneo, la promoción internacional de la obra de artistas de Asia, África y América Latina, el fomento de actividades internacionales para establecer redes de cooperación, y la promoción de las manifestaciones contemporáneas de artistas cubanos (Centro Wilfredo Lam, 1983 en Rojas-Sotelo, 2011, 164).

Siguiendo estos presupuestos, la segunda edición en 1986 (figura 2) suma a las obras de artistas de América Latina a producciones provenientes de Asia, África y del Medio Oriente. La tercera edición contará además con artistas de origen o residencia en Europa y Estados Unidos. A partir de esta tercera cita, en 1989, se decide eliminar el carácter competitivo y la división por países. Desde entonces cada edición se estructuraría alrededor de un concepto de reflexión - Tradición $y$ contemporaneidad para aquel año - que para el equipo curatorial representaba un tópico de interés dentro del debate internacional del arte contemporáneo. Esta estructura sigue funcionando hasta la actualidad. 

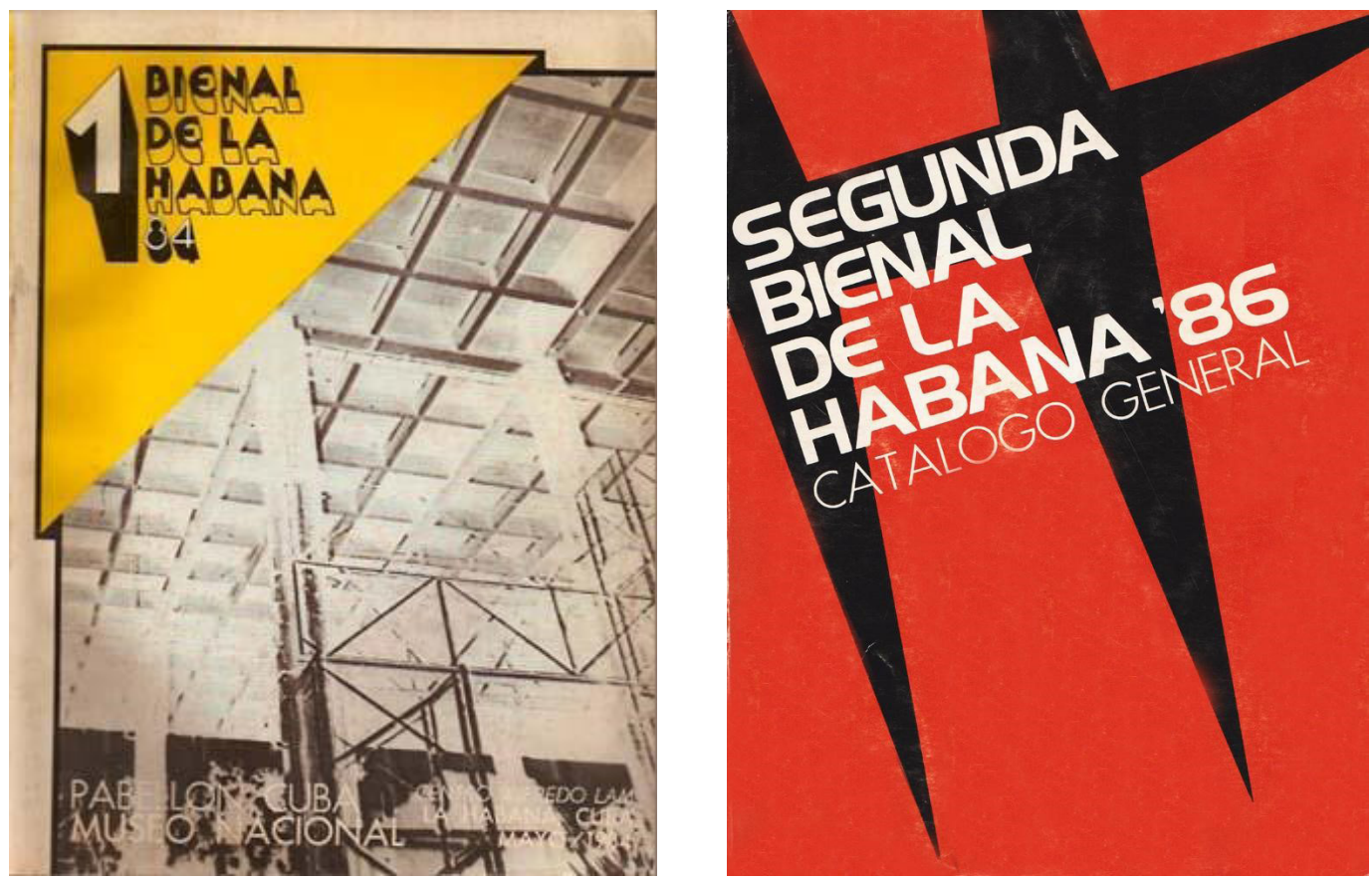

Figura 1 (izq.). Cartel de la I Bienal de La Habana, 1984.

Figura 2 (drcha.). Cubierta del catálogo general de la II Bienal de La Habana, 1986.

Según la investigadora Gabriela Piñero (2014), dibujar una cita tercermundista responde en el caso cubano a una serie de factores. Por un lado, como estrategia política del Ministerio de Cultura, que intentaba recolocar a Cuba en el escenario internacional — ante el inminente fin de la URSS y el consecuente fin de apoyo a la isla - y, por otra parte, posicionar a La Habana como centro del mapa del Tercer Mundo, al menos en la defensa de los aspectos culturales de este espacio. Debido a esto, el panorama artístico presentando en la Bienal estaba sincronizado con el de las solidaridades políticas del régimen cubano (1). Por otra parte, el proyecto de la Bienal estaba concebido como "una plataforma para revertir el desconocimiento y falta de intercambio entre países marginales, dentro del trazado de poder artístico" (Piñero, 2014, p. 175).

Una de las premisas de los organizadores de la Bienal era que para cambiar el orden de poder establecido por el régimen colonial, se hacía necesario luchar por un "nuevo orden internacional de la cultura" (Llanes en Piñero, 2014: 175), aliado a los cambios en el orden económico y de información. 
Exposiciones de arte global...

En la promoción de esta lucha se alcanzaba, según su concepción, un mayor conocimiento de la producción artística de las zonas marginadas. Para promover este mayor conocimiento la Bienal trata de

romper el esquema centro-periferia, sugiriendo que la ansiada globalidad del nuevo modelo expositivo consistía en la inclusión de artistas de todo el mundo sin ser etiquetados como mainstream [...] pero con una forma descentralizada de pensar lo global y articularlo micropolíticamente (Guasch, 2016: 115).

Estos objetivos aparecen claramente esbozados en el folleto de presentación de la I Bienal de La Habana cuando el poeta Eliseo Diego (1984: s/p) lo cierra con la siguiente aseveración:

La incomunicación entre los pueblos del Tercer Mundo ha sido una catástrofe alentada por las aviesas intenciones de imperialismos ya caducos o en trance de corrupta descomposición. La Revolución Cubana se ha propuesto con inquebrantable empeño romper toda barrera entre hermanos, reintegrar lo disperso. De aquí que esta I Bienal sea, no sólo un importante evento artístico, sino un hecho de significación histórica que ha de tener incalculables y consoladoras consecuencias para el futuro de todos.

El simbólico año 1989 también fue escenario The Other Story en la Tate Modern Gallery. Otra exposición que procura replantear el modelo hegemónico y proponer dispositivos expositivos globales. Reunió obras vanguardistas de artistas afro-británicos, caribeños y asiáticos y, como las otras muestras aquí reseñadas, recibió aclamaciones y burlas más o menos en la misma medida (2). 


\subsection{Magiciens de la Terre (Centre Georges Pompi- dou y Grande Halle at the Parc de la Villette, 1989)}

Magiciens de la Terre aunque haya sido analizada, alabada y criticada hasta el cansancio, sigue constituyendo un buen ejemplo para entender y problematizar los procesos inclusivos operados a finales de la década de 1980 (figura 3).

Algunas propuestas anteriores, con menos repercusión, buscaron incluir la producción artística de otras culturas o espacios geográficos —en una aproximación etnográfica al arte contemporáneo-, cayendo en la mayoría de las veces en la primitivización y en la exotización. Ejemplo de estos intentos fue Primitivism in 20th Century Art: Affinity of the Tribal and the Modern, exhibida en 1984 en el Museum of Modern Art (MoMA). Esta exposición más que profundizar en las reflexiones sobre el arte primitivo, le citará apenas como fuente de influencia formal para las obras de las vanguardias occidentales (Gradowska, 2004).

Por más críticas y reproches que recogiera Magiciens ... — realizada como una especie de respuesta a Primitivism in 20th...- es imposible negar, sin embargo, que ha marcado un hito en lo que se refiere a una idea global del arte. En consecuencia, se constituyó como un modelo latente para las muestras posteriores que buscarían una selección de la producción del arte de distintas regiones, ya fuera por replicar elementos que se consideran adelantos o por rebatir el despliegue neocolonialista que marcó sus elecciones. 
Exposiciones de arte global...

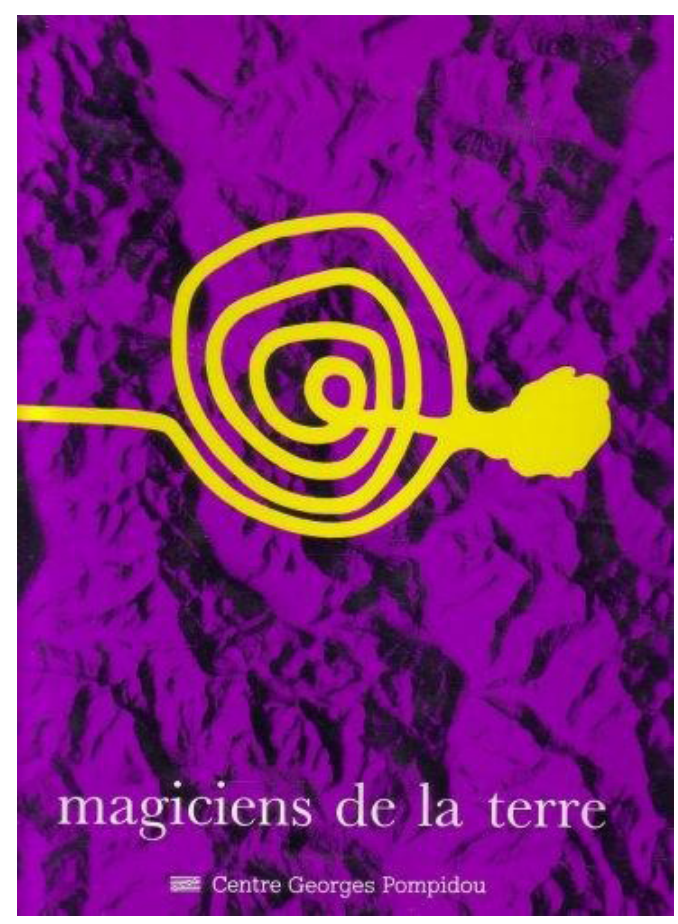

Figura 3. Cubierta del catálogo de la exposición Magiciens de la Terre. París:

Centre Georges Pompidou y Grande Halle at the Parc de la Villette, 1989.

La muestra fue comisariada por Jean-Hubert Martin y exhibida en el año de 1989 en París (3). Actualmente es considerada la primera muestra en proponer una idea universal del arte, con la presencia de artistas de las más distintas regiones del mundo. Aunque, como hemos defendido anteriormente II Bienal de La Habana había presentado esta configuración ya en el año 1986. De forma que, una mejor definición para Magiciens de la Terre, sería apuntarla como la primera muestra global organizada en un país del entonces llamado 'Primer Mundo', dentro de un prestigioso museo como el Centre Pompidou. Hechos que, por ende, le otorgaron reconocimiento, visibilidad y validación internacional.

En una fecha paradigmática como 1989, confluye la tercera edición de la Bienal de La Habana con Magiciens de la Terre. Fecha paradigmática porque es el año que se toma como término de la Guerra Fría, con una sugerente derrota de la Unión Soviética y una inmediata reorganización de la geopolítica global. Si vamos específicamente al caso cubano, el fin de la URSS suponía un riesgo del proyecto revolucionario iniciado exactamente tres décadas antes. 
Es el mismo momento en que se estaban sembrando las alternativas y urgencias de inclusión multicultural en una dualidad causa y efecto con los procesos históricos. En este contexto hay que entender estos dos eventos como ventanas de aquellos procesos, aunque en búsqueda de objetivos muy distintos. Entender la lejanía de estos objetivos se hace más comprensible si situamos los dos discursos. Mientras en Magiences de la Terre se construye la representación del "otro" desde una voz exterior, en la Bienal de La Habana, debido a su situación geopolítica, se intentó crear una narrativa compartida con la otredad.

Un texto analítico de comparación entre las dos citas fue escrito por el artista uruguayo Luis Camnitzer para la revista Third Text, donde reconocía que éstas fueron las grandes vitrinas del arte del Tercer Mundo, pese a sus insondables diferencias presupuestarias, con la salvedad de que en la muestra de La Habana las obras eran exhibidas de acuerdo con la contextualización dada por los artistas y no por estrategias curatoriales. Siguiendo este pensamiento, Camnitzer (en Guasch, 2016) hace el siguiente análisis:

Mientras las dos muestras plasmaron la libertad de mezclar arte elevado y arte popular, la de La Habana ignoró el concepto de moda de la 'otredad' [...] En París, la buscada 'otredad' determinó la intención así como la realización. Desde el inicio, el título abría las puertas al exotismo, a un arte que no seguía las normas hegemónicas y que a menudo no se definía a sí mismo como arte. La posibilidad de poseer la categoría de 'magos' compartida por artistas hegemónicos ayudaba a borrar la mala conciencia de los organizadores. La Habana no fue un foro para la 'otredad' (otherness), sino más bien para el thisness donde this es lo que nos define y no cómo somos definidos por otros (p. 115).

Distinto de las premisas que movían a Jean-Hubert Martin, la Bienal de La Habana "se anclaba en el argumento del tercermundismo como calificativo que denota la urgencia de una reestructuración de la identidad, no sólo desde la perspectiva artística y cultural, sino de la geografía de poderes" (Habib el Fakih, 2016, p. 32). 
Exposiciones de arte global...

La propuesta curatorial de Martin era la de dar a conocer la existencia de distintas formas estéticas en regiones que no habían sido cartografiadas por la historiografía del arte occidental. Así lo expresa en el comunicado de prensa (Magiciens de la Terre, 1989):

"Magiciens de la Terre" is the first exhibition really to take a global overview, taking into account revisions in the way in which traditions and developments have occurred throughout the 20th century, and believing that the time has come to look again at the categories, as well as the geographical and cultural boundaries, which have divided and prejudiced opinions on the relations between different cultures in the world (s.p.). (4)

Esta autoafirmación de la originalidad e innovación fue interpretada como una postura arrogante por los medios especializados, generando numerosas críticas tanto a la muestra como a la figura del comisario. Jean-Hubert Martin rebatió estas opiniones cuando, años después, reafirmando la herencia de Magiciens... dijo que el objetivo de la muestra había sido logrado o, al menos en parte, pues "impulsó a muchos colegas a buscar artistas fuera de los países de la OTAN" (Martin, Jean-Hubert en Fernández del Campo, 2012: s.p.), haciendo hincapié que hasta 1989, los límites del mundo del arte se restringían al entorno de la Alianza Militar, sin incluir siquiera a todos los rincones de Europa.

Entre tanto, las críticas más enérgicas a Magiciens... se originaron en la distinción realizada entre las obras y artistas provenientes de Europa y Estados Unidos frente aquellas obras de otros contextos estéticos. Como apunta Joaquín Barriendos (2015), "Magiciens... exibe por um lado a cinquenta artistas do lado bom da modernidade (modernismo euro-americano) e cinquenta do lado sombrio da modernidade (antropologicamente definidos como arte primitiva)” (p. 1) (5). Así, en su afán universalizante, al contrario de revisar categorías y sanar los prejuicios, lo que consigue es fortalecer la idea de una partición entre una estética occidental moderna y otra tercermundista periférica, cargada de exotismo, folclore y mitos. 
De un lado, el público podía ver las más recientes obras de arte contemporáneo occidental, de artistas consagrados o al menos familiarizados con las salas de museos. El team occidental se componía de nombres como el de Anselm Kiefer, Mario Merz, Louise Bourgeois, Daniel Burem, Claes Oldenburg, Hans Haacke y Barbara Kruger, por citar algunos.

Del "otro lado", cuestionando el concepto occidental del artista y vinculándolo con aspectos del mito y de la magia - como si fueran conceptos intrínsecos a las propuestas periféricas - , los magos de Magiciens exhibieron arquitecturas fantásticas del Zaire, estatuas funerarias de cemento de artistas de Benín, pinturas de tierra de aborígenes australianos, estatuas rituales, signos vudús y dibujos sobre arena.

Al analizar este conjunto de objetos descontextualizados de su entorno, resulta al menos interesante saber que los antropólogos/comisarios destinados a cartografiar esta estética de los márgenes, decidieron que las máscaras no deberían de entrar en la exhibición. Comentan que, aunque el público probablemente esperaba ver centenares de objetos de este tipo, no entraron en el criterio de selección pues "Mais le masque sans le corps est mort" (6) (Magnin, Luque y Gruénais, 1990, p. 57). En un intento de recontextualizar estos objetos dentro del espacio sacralizado del museo se pudo ver, en los meses que duró la muestra, una suerte de rituales performáticos que algunos de los productores/artistas tercermundistas realizaron frente al público.

La "actuación" de estos artistas periféricos fue defendida de la siguiente manera por los productores de la muestra: "Although it is clear that many works will be displaced from their 'original' context, we have found that the practice of making an ephemeral or site-specific work for a particular occasion cannot be restricted to contemporary western artists" (7) (Magiciens de la Terre, 1989, s.p.). Una vez más en el intento de reivindicar la modernidad no occidental se cayó en el equívoco de cargar de exotismo sus manifestaciones. En el lugar de dar voz al "otro", legitimando sus narrativas, lo que se vio en el resultado final fue la demarcación de la diferencia entre un quehacer estético occidental y desarrollado, de aquel otro, realizado en los espacios periféricos, primitivo y lejano a la percepción de la sociedad occidental. 
Como se ha dicho al comenzar el epígrafe, es indiscutible la importancia de $\mathrm{Ma}$ giciens de la Terre en la configuración de lo que se ha reconocido como muestras de arte global. Su importancia no radica en la definición de un modelo y de un conjunto de buenas prácticas sino más bien, por incluir la discusión del poder de la representación (y representatividad) del arte y de su lugar de enunciación en las pautas contemporáneas. Actualmente, pasadas casi tres décadas desde Magiciens... ¿cuánto de esta utopía del lenguaje franco y equitativo del arte global ha calado? Echar un vistazo a la lista de artistas que integraron la muestra de 1989 nos dará algunas pistas. Basta con buscar entre todos aquellos magos modernos o primitivos cuales son los que resuenan actualmente a oídos acostumbrados a museos y exposiciones para percibir que falta mucho para que realmente se abra un espacio ecuánime.

\subsection{The Decade Show: Frameworks of Identity in the 1980s. (Museum of Contemporary Hispanic Art, The New Museum of Contemporary Art y The Studio Museum Harlem 1990).}

La búsqueda del aspecto pluralista de las propuestas comisariales siguió su curso y en el año 1990 se inauguraría en los Estados Unidos una gran muestra articulada entre tres museos de Nueva York, titulada The Decade Show: Frameworks of Identity in the 1980s (8). La muestra reunió a más de 200 obras de 94 artistas estadounidenses de origen hispano, asiático, afroamericano, nativos americanos y europeos. La elección de las obras y artistas no estuvo basada en una simple revisión estilística, sino que se orientó hacia los temas prevalecientes, surgidos o reforzados en la década de 1980. De acuerdo con el folleto de la muestra (The Decade Show. Frameworks of Identity in the 1980s, 1990):

a la vez que se dirigen colectivamente al fenómeno de la exclusión, estos artistas recurren a diferentes combinaciones de experiencia personal, herencia cultural, sexo, sexualidad y puntos de vista políticos y filosóficos para interpretar los temas los temas que les ocupan (s.p.). 
Cada uno de los museos participantes en el proyecto: The New Museum, The Museum of Contemporary Hispanic Art y The Studio Museum Harlem, presentaron obras en los más distintos formatos manteniendo a su vez el cuño multicultural. El montaje fue dividido por ejes temáticos: costumbres sociales/ crítica cultural, historia/ memoria/ artefacto, biografía y sexualidad/ sexo, mitos/ espiritualidad/ naturaleza y diálogos/ medios de expresión, que se encontraban divididos entre las tres instituciones.

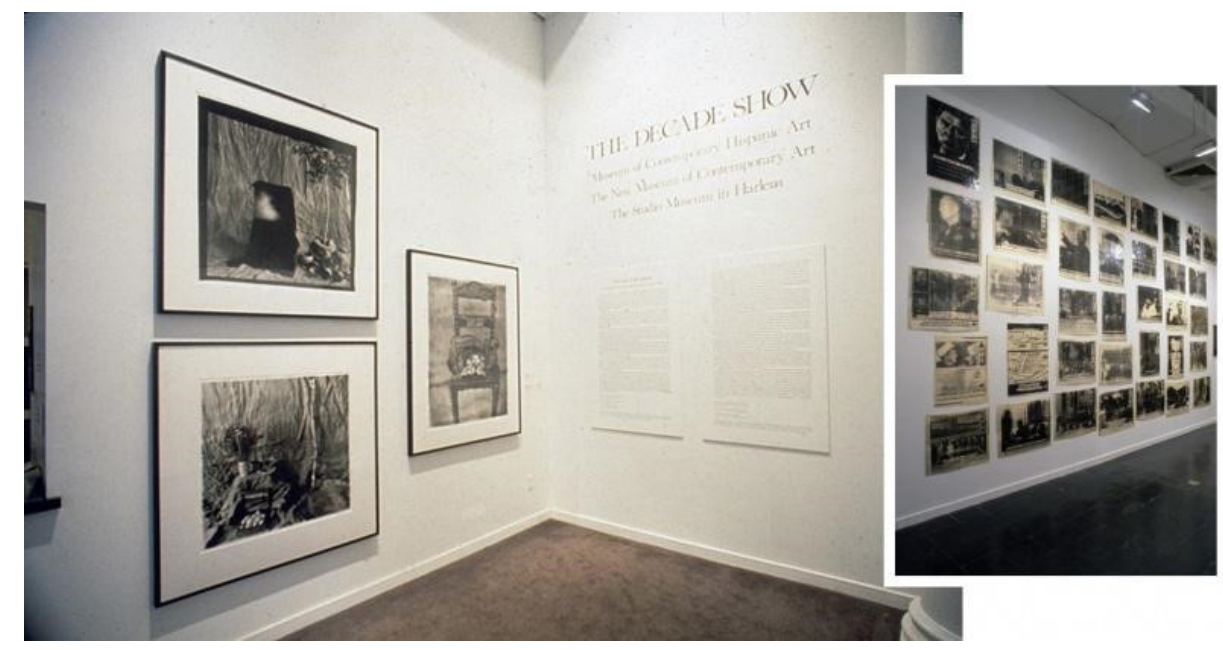

Figura 4. Vista de la exposición The Decade Show: Frameworks of Identity in the 1980s en el The New Museum, 1990. A la derecha la obra de Albert Chong, Rights: 36 Tactics, expuesta en la ocasión. Foto: http://www.newmuseum.org/

$$
\text { history }
$$

En medio de las inserciones de globalización cultural, precisamente en The Decade... la propuesta curatorial se alejó del concepto de la entidad del 'otro' por el de la identidad. Los artistas que tuvieron sus obras exhibidas en la exposición encarnaban su condición de 'otredad' en diferentes ópticas: desde su condición geográfica a su condición inmigrante y también, por tratar temas de otras minorías (de sexo, de orientación sexual, de ideologías, etc.). 
Exposiciones de arte global...

Al comprender estas complejas especificidades locales, lo que se intentó hacer en The Decade... fue salir de la condición pasiva del objeto de arte expuesto, en un recurso de alteridad, concediendo voz al artista para que estableciese su propio diálogo con el espectador. De acuerdo con Simon Njami (2010):

Aquí tenemos la identidad, anunciada como una cuestión esencial de la década. Se trata, sin duda, de la experiencia más audaz y justa desde un punto de vista intelectual, en la medida en que la inclusión no era el resultado de una entidad, sino que se realizaba por la suma de varias energías. En este verdadero trabajo de colaboración, el centro omnisciente y paternalista desaparece en favor de una dinámica con la que cada una de las instituciones implicadas, con identidades propias, se dejaba contaminar por las demás. Entre sus ventajas, estaba la opción que daba a los no occidentales para que dijeran su versión de la verdad, sin traducciones ni maquillajes bien intencionados (s.p.).

El objetivo de la exhibición no era el de promover un recuento enciclopédico de lo que se había producido en la década de los 80 en Estados Unidos y que generalmente había sido omitido por el discurso de las instituciones principales. Lo que buscaba era

celebrar y dar testimonio de la diversidad cultural. A través de las obras de los artistas participantes, de paneles de discusión interpretativa, obras de arte y ensayo, video y literatura, esta exposición se propone establecer un diálogo entre los diversos segmentos de la población norteamericana (The Decade Show. Frameworks of Identity in the 1980s, 1990, s. p.).

The Decade Show... se comprometió con la representación de la alteridad, cediendo al otro — dando visibilidad a diversas minorías, no solamente la geográfica — la interlocución con los espectadores y sobre todo, reconociendo estos otros como piezas integrantes de la pluralidad de voces de la sociedad norteamericana. 


\subsection{Documenta Xy documenta XI (Kassel, 1997 y 2002).}

Podemos apuntar como uno de los hitos en el cierre de la última década del milenio, la realización de la documenta X, en 1997 y su culminación con la documenta $X I$ en 2002. Estos eventos constituyen sin lugar a dudas el gran termómetro que verifica (y legitima) por donde se mueve la producción y el pensamiento del arte último, volcándose en analizar el momento en que vivía la cultura contemporánea con la edición de 1997, y afianzándose también como una cita global en la siguiente exposición.

La polémica curaduría de Catherine David en la documenta X (figura 5) propone una especie de retroperspective (9), en una mirada hacia atrás y adelante, tanto al arte como a la coyuntura misma de la muestra y sus relaciones políticas y sociales. Atendiendo a esta perspectiva no faltaron las propuestas y cuestionamientos sobre el poscolonialismo, sobre las distintas formas de urbanismo, sobre el significado de la imagen visual en la sociedad de la información y sobre la red y el comercio del arte contemporáneo (documenta X, 1997, s. p.).

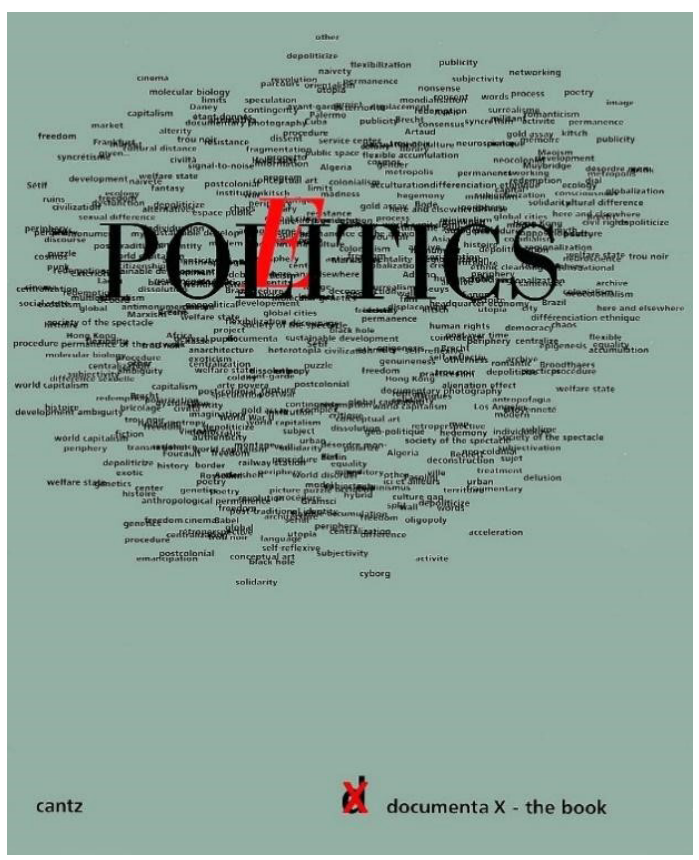

Figura 5. Politcs-poetics, documenta X: the book. Cubierta del libro/catálogo que acompañaba exposición. Kassel, 1997. 
La ruptura con el modelo tradicional de la edición documenta $X$ comienza con la elección de su dirección artística. Comandada por un comisario general no alemán, circunstancia que no ocurría desde su fundación en 1955 y, pasando esta responsabilidad por primera vez a manos de una mujer. Las exposiciones (con cerca de 700 obras de 120 artistas de todo el mundo) se complementaron con un programa cultural de debates llamado 100 Days - 100 Guests, donde participaron nombres como Edward Said, uno de los iniciadores de los estudios poscolonialistas; Okwui Enwezor, comisario y crítico de arte que sucedería la dirección artística de la documenta y que declara la inclusión periférica como impronta de sus propuestas.

En la presentación oficial, C. David insistió en el hecho que el 13\% de los artistas seleccionados para la muestra provenían de regiones del mundo no eurocéntricas. De acuerdo con el texto de Manuel Borja-Villel (2010), la documenta había surgido al principio de la Guerra Fría como una vitrina del arte occidental más actual frente al orden soviético. Tras la caída del muro en 1989 el certamen necesitaba reubicarse en el escenario internacional: “¿cuál podía ser su función en un mundo global en el que, con la caída del muro de Berlín, Kassel dejaba de tener su función inicial?” (Borja-Villel, 2010, s. p). La cita cuatrienal, por lo tanto, tuvo que encontrar un camino distinto desde dónde narrar la reconfiguración del poder internacional y dar sentido a su existencia. Sumado a esto, sería importante que Kassel mantuviese su apuesta recurrente por el arte más 'radical'.

Para lograr reposicionar la documenta el hilo conceptual encontrado por David fue hacer una retroperspective que auxiliase, en un momento de profundos cambios en las más distintas esferas, la realización de un recuento cultural hasta el presente para hacer posible una interpretación de la actualidad. De acuerdo con David, esa ecuación solamente sería posible aunando (o sobreponiendo) la poética estética con la política, pues "a la vista de las urgentes cuestiones de este tiempo, sería más que inconsecuente renunciar a toda exigencia ética y política" (David, Catherine en Comas, 1997, s.p.).

Entre tanto, la exposición propuesta por Catherine David, lejos de agradar y dar al público un entendimiento de la complejidad de las redes que empezaban a diseñar el mundo contemporáneo, recibió duras críticas por su desmedida intelectualización. 
En textos publicados en ocasión del discurso de apertura del certamen, comparaban el ambiente de la exposición — vaciada de figuración y con una excesiva presencia del video - con la arrogante postura del concepto curatorial (Comas, 1997). Pese a estas críticas, comunes en muestras de finales de siglo, no podemos obviar que la documenta $X$ supo "construir un modelo histórico que nos permitiese entender mejor un mundo ante cuyo proceso globalizador no podíamos permanecer ajenos" (Borja Villel, 2010, s.p.).

El museo de los 100 días — como se acostumbra llamar a la documenta-consolidará este discurso inclusivo en la siguiente edición (celebrada en 2002) presentado a un $30 \%$ de artistas no centrales en el proyecto de Okwui Enwezor. Enwezor, comisario nigeriano afincado en Estados Unidos, había sido director artístico de la II Bienal de Johannesburgo (10) en 1997 donde había demostrado su voluntad de reorientar las exposiciones, acentuando el carácter poscolonial y trasnacional que vivía la contemporaneidad, llegando a un modelo de exposición global (11).

Para el gran escaparate de la documenta XI, Enwezor desarrolla "un proyecto discursivo-expositivo que se propone superar lo poscolonial y lo multicultural por lo global" (Guasch, 2016, p. 135). Partiendo de la experiencia de Johannesburgo, la cita alemana contaba con la colaboración de seis vicecomisarios y cinco eventos sucesivos celebrados en ciudades de cuatro continentes: Viena y Berlín, Nueva Delhi, Santa Lucia y Lagos. Estos encuentros, fueron en realidad plataformas de investigación y contacto: "mapas de los circuitos del conocimiento contemporáneo acerca de arte, teoría, ciencia, cultura, ecología, especialidad y temporalidad, sistemas urbanos, localidad, globalidad, formaciones institucionales, etc" (Guasch, 2016, p. 135).

En esta documenta XI se exhibieron obras de casi 120 artistas procedentes de más de 40 países en las salas del Fridericianum Museum y en otras cinco sedes. Esta documenta, como prácticamente todas, no contentó a toda la crítica provocando una serie de discusiones y algo de revuelo en el medio artístico. Los reproches se centraban principalmente en el carácter extremadamente sociológico de las obras - había una presencia masiva de videos, fotografías y registros de acciones - que ofuscaban, según la crítica, el carácter sublime y contemplativo del arte (12). 
Victoria Combalia (2002) escribía en las páginas del periódico El País: "La obra de arte se va convirtiendo en una mera huella visual de un discurso sociológico con documentales" (s. p.).

Otra de las reprimendas de la crítica fue que la mayoría de los artistas periféricos presentes en la muestra producían desde los centros hegemónicos del arte o eran representados por galerías de ciudades como París, Nueva York y Londres. A esta crítica Enwezor argumentaba que se basaba en que la localidad de nacimiento de los artistas no importaba tanto dentro de una contemporaneidad inmersa en procesos de desplazamientos, redes y migraciones. La nacionalidad era lo de menos en una sociedad trasnacional y poscolonial. Esta negación de una particularidad dada por la identidad nacional era una especie de antídoto a Magiciens de la Terre, que exhibió junto a cada obra un mapa de localización del país natal del artista.

El medio especializado no obvió, entretanto, que la muestra fuera uno de los "acontecimientos más radicales en la historia de la práctica poscolonial [...] la novedad de la documenta 11 sería más curatorial y, en último término, un hito en el desarrollo no sólo de los discursos poscoloniales sino de la práctica artística poscolonial" (Guasch, 2016, p. 139). El modelo generado a partir de esta experiencia hizo que a escala mundial comenzaran a diseminarse grandiosas exposiciones

no sólo para facilitar un mejor conocimiento de los movimientos artísticos para el público global a través del uso simbólico y del intercambio de formas e ideas de un arte internacional avanzado, sino para propagar una cierta voluntad de arte global que no esconda las asimétricas relaciones de poder en las prácticas artísticas institucionales (Guasch, 2016, p. 141).

\section{Algunas consideraciones}

Si nos alejamos de los halagos o las críticas hacia estas muestras, sus objetivos, respuestas y dudas, tenemos que tener presente que estas fueron pioneras en la inserción de la producción del arte periférico a la autarquía que vivía el arte occidental hasta aquellos momentos. 
Entrada la década de 1990 la organización de exposiciones de arte que buscaban y buscan reacomodar el espacio para la producción antes renegada será cada vez más numerosa. Empieza a entenderse que establecer a este "otro" visible e incorporarlo en la escena artística y cultural implica nuevas concepciones de programas artísticos y eventos culturales donde sea posible promover la circulación de las diferencias.

Entre los objetivos se buscará entonces crear espacios de posibles encuentros multiculturales, organizándolos mediante distintas categorías. Según Cecilia Iida (2016, p. 23), en estas exposiciones los modelos curatoriales justifican y valoran un modo de articulación del mundo, una forma de pensarlo que hace del circuito artístico internacional un espacio de disputa por la legitimidad, así como también de emergencia de alternativas de sentido y prácticas diversas.

Al retomar estas exposiciones y analizar sus implicaciones, nos acordamos de un planteamiento de N. García Canclini (2013, s.p.), quien afirma que estas muestras buscaron "compaginar la multiculturalidad fragmentada que celebró el posmodernismo tratando de que el desorden sea interpretable". Creemos que en estas exposiciones se intentó representar la pluralidad de conformación de la sociedad contemporánea que empezaba a exigirse desde los presupuestos poscoloniales. Tanto con sus fallos y problemáticas, hay que reconocerlas como los primeros tanteos de construir la representación estética de los márgenes.

Estas narrativas se forjaron a partir de las herramientas manejadas en cada uno de los espacios donde fueron construidas: una propuesta con fuerte matiz comparatista en Magiciens de la Terra, un discurso que se escribe desde los márgenes en la Bienal de la Habana, enmarcando las distintas identidades y trasladando el poder de la representación hacia las minorías en The Decade Show... o, la narrativa intelectualizada, exclusiva y oficialista comúnmente utilizada en la documenta.

La importancia de estas exposiciones - como iniciadoras de este proceso de inclusión de la estética periférica en el sistema central de arte - nos ha llevado a cuestionar los sistemas de representación y, percibiendo desde dónde se construyen estas narrativas, entender el modo en que estos sistemas reafirman los esquemas de poder que se solidificaron a nivel global (Hall, 1992). 


\section{Notas}

(1) La investigadora argentina G. Piñero (2014) añade que de acuerdo con Gerardo Mosquera - uno de los ideadores la muestra - y Rachel Weiss a pesar de contar la Bienal con relativa independencia, al menos hasta la cita de 1989, las decisiones sobre países y artista incluidos estaban mediadas por los intereses del Estado cubano.

(2) Para ampliar sobre la exposición Other Story ver: Fischer, J. (2009). The Other Story and the Past Imperfect. Tate Papers, 12. Recuperado de http://www.tate.org.uk/research/publications/tate-papers/no-12/the-other-story-and-the-past-imperfect. y Guasch (2016).

(3) Magiciens de la Terre se exhibió del 18 de mayo al 14 de agosto de 1989.

(4) "Magiciens de la Terre" es la primera exposición que tiene realmente una visión global, tomando en cuenta las revisiones tradicionales y los desarrollos que han ocurrido a lo largo del siglo XX, y creyendo que ha llegado el momento de revisar las categorías, así como las fronteras geográficas y culturales, que han dividido y perjudicado las opiniones sobre las relaciones entre las diferentes culturas del mundo. (Traducción de la autora)

(5) "Magiciens exhibe por un lado a cincuenta artistas del lado bueno de la modernidad (modernismo euro-americano) y cincuenta del lado oscuro de la modernidad (antropológicamente definidos como arte primitivo)”. (Traducción de la autora).

(6) "Pues la máscara sin cuerpo está muerta" (Traducción de la autora).

(7) "Aunque está claro que muchas obras serán desplazadas de su contexto "original", hemos encontrado que la práctica de realizar una obra efímera o específica para un lugar en una ocasión particular no puede limitarse a los artistas occidentales contemporáneos". (Traducción de la autora)

(8) The Decade Show. Frameworks of Identity in the 1980s se celebró en el Museum of Contemporary Hispanic Art del 16 de mayo al 19 de agosto de 1990; The New Museum Of Contemporary Art del 12 de mayo al 19 de agosto de 1990; y The Studio Museum Harlem del 18 de mayo hasta el 19 de agosto de 1990. 
(9) David sostiene que la documenta $X$ tiene la obligación de elaborar una mirada histórica y crítica sobre su propia historia. Propone de esta manera una retroperspective: "certain major proposals that appeared in the 1996s in the work of artists who were born before, during, or immediately after the war, some of whom died prematurely (Marcel Broodthaers, Öyvind Fahlström, Gordon Matta-Clark, Hélio Oiticica), and almost all of whom began their work around the time that the first documenta opened (Gerhard Richter, Michelangelo Pistoletto, Richard Hamilton, Aldo van Eyck)". David, C. (1997). Introduction in the Short Guide. Comunicado de prensa. Recuperado de http://www.universes-in-universe.de/doc/e_press.htm.

(10) La II Bienal de Johannesburgo tuvo lugar del 12 de octubre al 12 de diciembre de 1997.

(11) Para la cita de Johannesburgo Enwezor, intentando esquivar el tono nacionalista y el gran poder de autoría del comisario, invitó a seis curadores de distintas regiones, con la única restricción de que sus proyectos no estuvieran basados en criterios de nacionalidad y rebasaran su inclinación territorial. Fueron invitados Gerardo Mosquera, de Cuba; Hou Hanru de China con residencia en París; Yu Yeon Kim, que alterna entre Seúl y Nueva York; Octavio Zaya, de España, con residencia en Nueva York y que trabajó intensamente con artistas de Europa, África y América Latina; Kellie Jones de los EE.UU.; y Colin Richards de Sudáfrica. Es clave percibir en los comisarios invitados el aspecto de transitoriedad de sus currículos, el "between” (la interrelación espacial) que defendía Enwezor en sus proyectos para poder identificar estas zonas de contacto en el terreno poscolonial. Sobre este tema véase Guasch (2016).

(12) En las publicaciones de la prensa española podemos ver varias de estas críticas, como en: Acosta, J. M. (07 de junio de 2002). La Documenta de Kassel antepone la protesta a la estética. ABC.es Recuperado de http://www.abc. es/hemeroteca/historico-07-06-2002/Cultura/la-documenta-11-de-kassel-antepone-la-protesta-a-la-estetica_104950.html; Krauthausen, C. (9 de junio de 2002). La Documenta explora los géneros de arte. El País. Recuperado de : http://elpais. com/diario/2002/06/09/cultura/1023573601_850215.html; y Combalia, V. (18 de julio de 2002). La Documenta 11 o el triunfo del realismo. El País. Recuperado de: http://elpais.com/diario/2002/07/18/catalunya/1026954440_850215.html. 
Exposiciones de arte global...

\section{Referencias}

Gradowska, A. (2004). La pluralidad y el ascenso de las culturas del "Tercer Mundo". En A. Gradowska. El otoño de la edad moderna (Reflexiones so bre el postmodernismo. Caracas, Universidad Central de Venezuela y Con sejo de Desarrollo Científico y Humanístico, pp. 133-137.

Barriendos, J. (2015). Confluência esférica. Curadoria global após "Magiciens de la Terre". Art Research Journal 2(2), pp. 1-14.

Borja-Villel, M. (30 de julio de 2010). La última Documenta del siglo XX”. El mundo. El cultural. Recuperado de http://www.elcultural.com/revista/arte/ La-ultima-Documenta-del-siglo-XX/27694.

Comas, J. (20 de junio de 1997). La Documenta X propone en Kassel 100 días de debate y un museo abierto a la polémica. El País. Recuperado de https:// elpais.com/diario/1997/06/20/cultura/866757601_850215.html.

Diego, E. (1984). Introducción. $1^{a}$ Bienal de la Habana. La Habana, Centro de Arte Contemporáneo Wifredo Lam y Consejo Nacional de Artes Plásticas, 1984. Recuperado de http://www.wlam.cult.cu/images/bienales/1.1BH. pdf.

Documenta X (1997). Recuperado de http://www.documenta.de/es/retrospective/ documenta_x.

Fernández del Campo, E. (2012). Entre las ideas y los objetos. Una conversación con Jean-Hubert Martin. Minerva (20), s.p. Recuperado de:http://www. circulobellasartes.com/revistaminerva/articulo.php?id=528.

García Canclini, N. (2013). Venecia o la geopolítica del arte. Rooots and Routes.Research on visual cultures, 11, s/p. Recuperado de http://www. roots- routes.org/speciale-55-biennale-di-veneziavenecia-o-la-geopoliti ca-del-artedi-nestor-garcia-canclini/ 
Guasch, Ana María. (2000). El arte último del siglo XX. Del posminimalismo a lo multicultural. Madrid: Alianza Editorial.

Guasch, A. M. (2016). El arte en la era de lo global 1989 / 2015. Madrid, Alian za Forma.

Habib El Fakih, Y. (2015). Genealogía del giro etnográfico en los discursos curatoriales contemporáneos (1989 - 2013). Trabajo final de Máster inédito, Universitat de Barcelona. Recuperado de http://diposit.ub.edu/ dspace/bitstream/2445/63003/1/TFM_Habib_2015.pdf.

Hall, S. (1992). Occidente y el resto: discurso y poder. En Hall, S. y Gieben, B. Formations of Modernity. Cambridge: Polity Press y Open University. Recuperado de http://www.unicauca.edu.co/ublogs/seminariopensamien to/wp-content/uploads/sites/3/2014/09/occidente-y-el-resto.pdf

Iida, C. (2016). El arte local en el contexto global. Cuaderno 60. Cuadernos del Centro de Estudios en Diseño y Comunicación, 60, pp. 21-29.

Magiciens de la Terre (1989). Comuniqué de Presse. Recuperado de https://www. centrepompidou.fr/media/document/12/95/1295983deb4ee5df99f92ab 974855fe0/normal.pdf Fecha de consulta: 15-V-2014.

Magnin, A.; Luque, A.; Gruénais M.C. (1990). Magiciens de la terre. Bulletin de l'Association française des anthropologues (39), pp. 55-67.

Mignolo, W. D. (2003). Historias locales; Diseños globales: colonialidad conocimientos subalternos y pensamiento fronterizo. Madrid: Akal.

Pacheco, M. (1999). Arte latinoamericano: ¿Quién, cuándo, cómo, cuál y dónde? Contextos y mundos posibles. En Jiménez, J. y Castro, F. (ed.). Notas del arte latinoamericano, pp. 127-140. Madrid: Editorial Tecnos; Conselleria de Cultura, Educació i Ciència, Direcció General de Promoció Cultural, Museus i Belles Arts, de la Generalitat Valenciana, 
Exposiciones de arte global...

Piñero, G. A. (2014). Políticas de representación/ políticas de inclusión. La reactualización del debate de lo latinoamericano en el arte durante la prim era etapa de la globalización (1980-1990). Anales del Instituto de Investi gaciones Estéticas, XXXVI (104), pp. 157-186.

Quijano, A. (1992). Colonialidad y modernidad/racionalidad. En Bonilla, H. (comp.). Los conquistados. 1492 y la población indígena de las Américas. Bogotá: Flacso, Ediciones Libri Mundi y Tercer Mundo Editores.

Rojas-Sotelo, M. (2011). The Other Network: The Havana Biennale and the Global South, The Global South, 5 (1), pp. 153-174.

Said, E. (2004 originalmente publicado en 1978). Orientalismo. Barcelona: De Bolsillo.

\section{¿Cómo citar este artículo?}

Ribeiro dos Santos, R. (Julio-diciembre,2018). Exposiciones de arte global como idearios de redefinición geopolítica y social a finales del siglo XX. Revis ta humanidades, 8 (2), 1-27. 